\title{
Expression and functions of N-type Cav2.2 and T-type Cav3.1 channels in rat vasopressin neurons under normotonic conditions
}

\author{
Kaori Sato-Numata ${ }^{1,2}$, Tomohiro Numata $^{2}$, Yoichi Ueta ${ }^{3}$ and Yasunobu Okada ${ }^{4 *}$ (i)
}

\begin{abstract}
Arginine vasopressin (AVP) neurons play essential roles in sensing the change in systemic osmolarity and regulating AVP release from their neuronal terminals to maintain the plasma osmolarity. AVP exocytosis depends on the $\mathrm{Ca}^{2+}$ entry via voltage-gated $\mathrm{Ca}^{2+}$ channels (VGCCs) in AVP neurons. In this study, suppression by siRNA-mediated knockdown and pharmacological sensitivity of VGCC currents evidenced molecular and functional expression of N-type Cav2.2 and T-type Cav3.1 in AVP neurons under normotonic conditions. Also, both the Cav2.2 and Cav3.1 currents were found to be sensitive to flufenamic acid (FFA). TTX-insensitive spontaneous action potentials were suppressed by FFA and T-type VGCC blocker Ni ${ }^{2+}$. However, Cav2.2-selective $\omega$-conotoxin GVIA failed to suppress the firing activity. Taken together, it is concluded that Cav2.2 and Cav3.1 are molecularly and functionally expressed and both are sensitive to FFA in unstimulated rat AVP neurons. Also, it is suggested that Cav3.1 is primarily involved in their action potential generation.
\end{abstract}

Keywords: Cav channel, Vasopressin neuron, Flufenamic acid, Action potential

\section{Background}

Arginine vasopressin (AVP) neurons that are located at the supraoptic nucleus (SON) and paraventricular nucleus (PVN) in the hypothalamus of the brain are a key player in maintaining the osmolarity of body fluid in a narrow range around 300 mOsm by secreting AVP from their neuronal terminals at the posterior pituitary gland. The action potential firing involves activation of $\mathrm{Na}^{+}$and $\mathrm{Ca}^{2+}$ conductance in the magnocellular neurosecretory cells (MNCs) consisting of AVP neurons and oxytocin (OXT) neurons [1-3]. The amount of vesicular exocytotic release of AVP from neurohypophysial terminals of MNCs is determined by the frequency and pattern of action potential firing [4] and by the entry of

*Correspondence: okada@nips.ac.jp

${ }^{4}$ National Institute for Physiological Sciences, 5-1 Higashiyama, Myodaiji, Okazaki, Aichi 444-8787, Japan

Full list of author information is available at the end of the article
$\mathrm{Ca}^{2+}$ via voltage-gated $\mathrm{Ca}^{2+}$ channels (VGCCs or Cav channels) [5]. Somatodendritic expression of L-, T- and $\mathrm{N}$-type VGCCs in rat supraoptic AVP neurons was suggested based on pharmacological studies on the increases in the intracellular free $\mathrm{Ca}^{2+}$ concentration $\left(\left[\mathrm{Ca}^{2+}\right]_{\mathrm{i}}\right)$ in response to application of AVP [6] and pituitary adenylate cyclase-activating polypeptide (PACAP) [7]. Besides, nifedipine-sensitive L-type $\mathrm{Ca}^{2+}$ currents were found to be increased in rat supraoptic MNCs under dehydration conditions produced after water deprivation for 16-24 h [8]. However, it is not known which types of VGCCs are expressed and functioning during the spontaneous action potential firing in unstimulated rat AVP neurons under normotonic conditions. The present study thus aimed to address this question by cytosolic RTPCR analysis and by whole-cell patch-clamp recordings in dissociated rat AVP neurons identified by transgenic expression of enhanced green fluorescent protein (eGFP) under the control of the AVP promoter [9]. RT-PCR, 
pharmacology, and gene silencing studies showed that both $\mathrm{N}$-type Cav2.2 and T-type Cav3.1 $\mathrm{Ca}^{2+}$ channels are molecularly and functionally expressed in dissociated rat AVP neurons under normotonic conditions and also that these VGCC currents are sensitive to an anthranilic acid derivative, flufenamic acid (FFA). Furthermore, pharmacological data suggested that T-type Cav3.1 (but not $\mathrm{N}$-type Cav2.2) channels are primarily involved in tetrodotoxin-insensitive spontaneous action potential firing in dissociated rat AVP neurons under normotonic conditions without any receptor stimulation.

\section{Methods}

\section{Animals and preparation of acutely dissociated AVP neurons}

All procedures involving animals were approved in advance by the Ethics Review Committee for Animal Experimentation of Fukuoka University and were in accordance with the guidelines of the Physiological Society of Japan. Non-transgenic female Wistar rats (Charles River Laboratories Japan, Yokohama, Japan) and heterozygous transgenic male Wistar rats, which express an AVP-enhanced green fluorescent protein (eGFP) fusion gene [9], were bred and housed under standardized conditions (12-h/12-h light/dark cycle) with food and water. For all the experiments, 4- to 5-week-old AVP-eGFP transgenic female rats were used.

Acutely dissociated AVP neurons were prepared, as described previously [10], and incubated in Ringer solution containing (in $\mathrm{mM}$ ): $140 \mathrm{NaCl}, 5 \mathrm{KCl}, 1 \mathrm{MgCl}_{2}, 2$ $\mathrm{CaCl}_{2}, 10$ HEPES and 10 glucose (adjusted to $\mathrm{pH} 7.25$ with Tris, 300 mosmol $\mathrm{kg}-\mathrm{H}_{2} \mathrm{O}^{-1}$, bubbled with $100 \%$ $\left.\mathrm{O}_{2}\right)$ at room temperature $\left(22-26^{\circ} \mathrm{C}\right)$. In all of the experiments, eGFP expression was confirmed each time under a fluorescence microscope to identify given $\mathrm{SON}$ neurons as AVP neurons.

\section{Cytosolic quantitative real-time PCR}

Using the RNeasy Micro Kit (Qiagen, Tokyo, Japan), total cellular RNAs were extracted from cytosol suctioned into patch pipettes from 10 AVP neurons and pooled. RNA samples were reverse-transcribed using the ReverTra Ace qPCR RT Master Mix with gDNA Remover (TOYOBO, Osaka, Japan) according to the manufacturer's protocols. Gene-specific primers used for PCR were designed with Primer3 software (https://bioinfo.ut.ee/primer3/) and NCBI BLAST (https://blast.ncbi.nlm.nih.gov/Blast.cgi) to identify complementary sequences in the rat genome. The following primers were used: $5^{\prime}$-CAGTGCGTGTTT GTTGCTATCCG-3' (forward) $/ 5^{\prime}$-TTTGGGGATGTA ACACCTCAGCG-3' (reverse) for Cav1.1 (GenBank accession no. NM_053873.1, product size 558); 5'-CAG CTGTTTGGTGGAAAGTTCA- $3^{\prime}$ (forward) $/ 5^{\prime}$-TGT
TGATCTTGGTAGTGGGTGG-3' (reverse) for Cav1.2 (GenBank accession no. NM_012517.2, product size 457); 5'-TCAATGGAAGCGTGTGTCCTCG-3' (forward)/5' ACATTCTGTCTTCTGGGGCTGG-3' (reverse) for Cav1.3 (GenBank accession no. NM_017298.1, product size 403); 5'-CGAGGATTTCGGTGTCTCTAC CCA-3' (forward) $/ 5^{\prime}$-TTGCAGACACTGGATGGT GAAGG-3' (reverse) for Cav1.4 (GenBank accession no. NM_053701.1, product size 404); 5'-CAAGAACTCCGG GATCCAAAAAC-3' (forward) $/ 5^{\prime}$-CAGCTCCACCCT TTGCGATTT-3' (reverse) for Cav2.1 (GenBank accession no NM_012918.3, product size 428); 5'-AGGCCA GACATGAAGACACACA-3' (forward) $/ 5^{\prime}$-TTGCCT TCCTTGCTTGAGTCCT-3' (reverse) for Cav2.2 (GenBank accession no. NM_001195199.1 and NM_147141.1, product size 422); and $5^{\prime}$-TGCTGTATAACGGCATCC GCTC-3' (forward) $/ 5^{\prime}$-TCTGGTTGTCCAGGACGC TAGT-3' (reverse) for Cav2.3 (GenBank accession no NM_019294.2, product size 570); 5'-ACGGGACCT GAAGAAGTGCTAC-3' (forward) $/ 5^{\prime}$-ATCGACTCT CCGGAAGTTCTGC-3' (reverse) for Cav3.1 (GenBank accession no. NM_001308302.1 and NM_031601.4, product size 586); and 5'-ATCAATCCCACCATCATC CGCA-3' (forward) $/ 5^{\prime}$-ACCTTGGCTTTCCTGTGC TGTA-3' (reverse) for Cav3.2 (GenBank accession no NM_153814.2, product size 579); and 5'-CAGCCTACA GACCACACTGGAA-3' (forward) $/ 5^{\prime}$-TCTTCCTTT TGCTCGCAGCATC-3' (reverse) for Cav3.3 (GenBank accession no NM_020084.3, product size 587). As a positive control, we amplified the glyceraldehyde3-phosphate-dehydrogenase (GAPDH) sequence with the following set of primers: $5^{\prime}$-CATGCCGCCTGGAGA AACCTGCCA-3 ${ }^{\prime}$ (forward) $/ 5^{\prime}$-GGGCTCCCCAGG CCCCTCCTGT-3' (reverse) (GenBank accession no. NM_017008.3, product size 429). As a negative control, we performed RT-PCR without reverse transcriptase. PCR was performed with $0.02 \mathrm{U} \mathrm{L}^{-1}$ of KOD -Plus- Neo $\mathrm{Taq}$ (TOYOBO). Amplification was carried out in a thermal cycler (Tadvanced 96 SG: Biometra, Göttingen, Germany) under the following conditions: initial heating at $94{ }^{\circ} \mathrm{C}$ for $2.5 \mathrm{~min}$, followed by 40 cycles of denaturation at $94{ }^{\circ} \mathrm{C}$ for $15 \mathrm{~s}$, annealing at $60{ }^{\circ} \mathrm{C}$ for $30 \mathrm{~s}$ and extension at $68{ }^{\circ} \mathrm{C}$ for $1 \mathrm{~min}$, and then final extension at $68^{\circ} \mathrm{C}$ for $5 \mathrm{~min}$. The products of RT-PCR were electrophoresed on a $2 \%$ agarose gel and then cloned into the pGEM$\mathrm{T}$ Easy vector (Promega, Tokyo, Japan) after purification with the Wizard SV Gel and PCR Clean-Up System (Promega). Plasmids were purified with the Wizard Plus Minipreps DNA Purification System (Promega) and used as templates for sequencing by FASMAC (Kanagawa, Japan). Quantitative real-time PCR and data analysis were performed using an ABI 7500 Fast Real-Time PCR System (Applied Biosystems, Foster City, CA, USA). 
Amplifications were performed using KOD SYBR qPCR Mix (TOYOBO) according to the manufacturer's instructions of annealing at $57{ }^{\circ} \mathrm{C}$ in a $20-\mu \mathrm{L}$ reaction volume containing $100 \mathrm{ng}$ cDNA. Gene-specific primers were same as those used in the PCR.

\section{Modification of gene expression and culture of acutely dissociated AVP neurons}

To reduce the expression of rat Cav2.2 and Cav3.1, siRNA-mediated knockdown was performed in AVP neurons. Fifteen minutes after acutely dissociated AVP neurons were plated on coverglasses, Ringer solution were replaced with Neurobasal Plus medium (Gibco, NY, USA) supplemented with $0.5 \mathrm{mM} \mathrm{L-glutamine,} 25 \mu \mathrm{M}$ glutamate, 1/50-diluted B-27 Plus Supplement (50X; Gibco), $100 \mathrm{U} \mathrm{mL}^{-1}$ penicillin, and $0.1 \mathrm{mg} \mathrm{mL}^{-1}$ streptomycin (Gibco). For siRNA transfection, Lipofectamine RNAiMAX transfection reagent (Invitrogen, CA, USA) was employed according to the manufacture's protocols. siRNAs conjugated with DY547 for Cav2.2 (Cat No. J-097736-10), Cav3.1 (Cat No. L-089308-02), and negative control (Cat No. D-001810-01) were designed and synthesized by Thermo Fischer Scientific (Tokyo, Japan). AVP neurons after siRNA transfection were incubated in a $95 \%$ air $/ 5 \% \mathrm{CO}_{2}$ atmosphere at $37^{\circ} \mathrm{C}$ for $24-60 \mathrm{~h}$, and were used for experiments.

\section{Electrophysiology}

The patch electrodes had a resistance of around 1-3 $\mathrm{M} \Omega$. Currents or voltages were recorded using an Axopatch 200B amplifier (Axon Instruments, CA, USA) coupled to DigiData 1440A A/D and D/A converters (Axon Instruments). Currents or voltage signals were filtered at $5 \mathrm{kHz}$ and digitized at $20 \mathrm{kHz}$. pClamp software (version 9.0.2: Axon Instruments) was used for command pulse control, data acquisition and analysis. For the measurements of $\mathrm{Ca}^{2+}$ channel currents, whole-cell voltageclamp recordings were performed at room temperature. The time course of current activation was monitored by repetitively applying (every $10 \mathrm{~s}$ ) alternating pulses (0.3-s duration) of $-10 \mathrm{mV}$ or $+10 \mathrm{mV}$ from a holding potential of $-80 \mathrm{mV}$. To observe voltage dependence of the current profile, step pulses were applied (every $10 \mathrm{~s}$ ) from the holding potential of $-80 \mathrm{mV}$ to test potentials of -60 or $-70 \mathrm{mV}$ to $+70 \mathrm{mV}$ for $0.3 \mathrm{~s}$ in $10 \mathrm{mV}$ increments. Series resistance $(<10 \mathrm{M} \Omega$ ) was compensated (to $70-80 \%)$ to minimize voltage errors. The intracellular (pipette) solution contained (in mM): 160 NMDG-phosphate, $4 \mathrm{MgCl}_{2}, 40$ HEPES, 10 EGTA, 12 phosphocreatine, 0.1 leupeptin, 2 ATP-Tris salt and 0.4 GTP-Tris salt (280 mosmol $\mathrm{kg}-\mathrm{H}_{2} \mathrm{O}^{-1}$, adjusted to $\mathrm{pH} 7.2$ with phosphoric acid). Normotonic extracellular (bath) solution (300 mosmol kg- $\mathrm{H}_{2} \mathrm{O}^{-1}$ ) contained (in $\mathrm{mM}$ ): 60 or 156
TEA-Cl, 10 HEPES, 50 or $2 \mathrm{BaCl}_{2}, 10$ glucose and 80 or 0 mannitol (adjusted to pH 7.3 with TEA-OH). For the measurements of membrane potential and spontaneous firing, perforated whole-cell current-clamp recordings were performed at $32-35{ }^{\circ} \mathrm{C}$ controlled by using a thermo-controller (WARNER Instruments, Hamden, $\mathrm{CT}$ ) with the pipette solution containing (in $\mathrm{mM}$ ) $99 \mathrm{~K}_{2} \mathrm{SO}_{4}, 31 \mathrm{KCl}, 5 \mathrm{MgCl}_{2}, 0.2$ EGTA, and 5 HEPES (280 mosmol kg- $\mathrm{H}_{2} \mathrm{O}^{-1}$, adjusted to $\mathrm{pH} 7.4$ with $\mathrm{KOH}$ ). Pipette solution was placed in the tip of the pipette by capillary action $(\sim 5 \mathrm{~s})$, and then pipettes were backfilled with nystatin-containing $\left(200 \mu \mathrm{g} \mathrm{mL}^{-1}\right)$ pipette solution. The normotonic bath $\left(300\right.$ mosmol $\left.\mathrm{kg}-\mathrm{H}_{2} \mathrm{O}^{-1}\right)$ solution contained (in mM) $120 \mathrm{NaCl}, 5 \mathrm{KCl}, 2 \mathrm{CaCl}_{2}, 1 \mathrm{MgCl}_{2}, 10$ glucose, 10 HEPES, and 100 mannitol (adjusted to $\mathrm{pH} 7.3$ with $\mathrm{NaOH}$ ).

\section{Statistical analysis}

Data were given as the mean \pm SEM of observations ( $n$ ). Statistical differences of the data were evaluated using one-way ANOVA followed by a Bonferroni-type post hoc multiple comparisons and considered to be significant at $P<0.05$.

\section{Chemicals}

All chemicals were prepared on the day of the experiments by diluting stock solutions with 1000 -fold concentrations. The stocks of flufenamic acid (Sigma-Aldrich, Tokyo, Japan), TTA-P2 (Alomone labs, Jerusalem, Israel), and ML218 (Sigma-Aldrich) were made in dimethyl sulfoxide (DMSO: Wako Pure Chemical, Osaka, Japan) and kept at $-20{ }^{\circ} \mathrm{C}$. The stocks of tetrodotoxin (SigmaAldrich), $\omega$-conotoxin GVIA (PEPTIDE INSTITUTE, INC., Osaka, Japan), $\omega$-agatoxin-IVA (PEPTIDE INSTITUTE, INC.), $\omega$-conotoxin MVIIC (PEPTIDE INSTITUTE, INC.), and SNX-482 (PEPTIDE INSTITUTE, INC.) were made in distilled water and kept at $-20^{\circ} \mathrm{C}$. $\mathrm{Ni}^{2+}$ (Wako Pure Chemical) was directly dissolved in the solution for each experiment and used within that day.

\section{Results}

\section{$\mathrm{N}$-type Cav2.2 and T-type Cav3.1 channels are molecularly} and functionally expressed in rat AVP neurons under unstimulated normotonic conditions

First, we performed RT-PCR for VGCC genes on the total RNA extract from pooled cytosols suctioned into patch pipettes from 10 individual eGFP-expressing AVP neurons isolated from the transgenic rat. As shown in Fig. 1, we actually observed bands of the size predicted for the mRNAs encoding all the brain members of VGCC: Cav1.2, Cav1.3, Cav2.1, Cav2.2, Cav2.3, Cav3.1, Cav3.2 and Cav3.3, whereas no PCR product was amplified when reverse transcriptase was omitted from the 


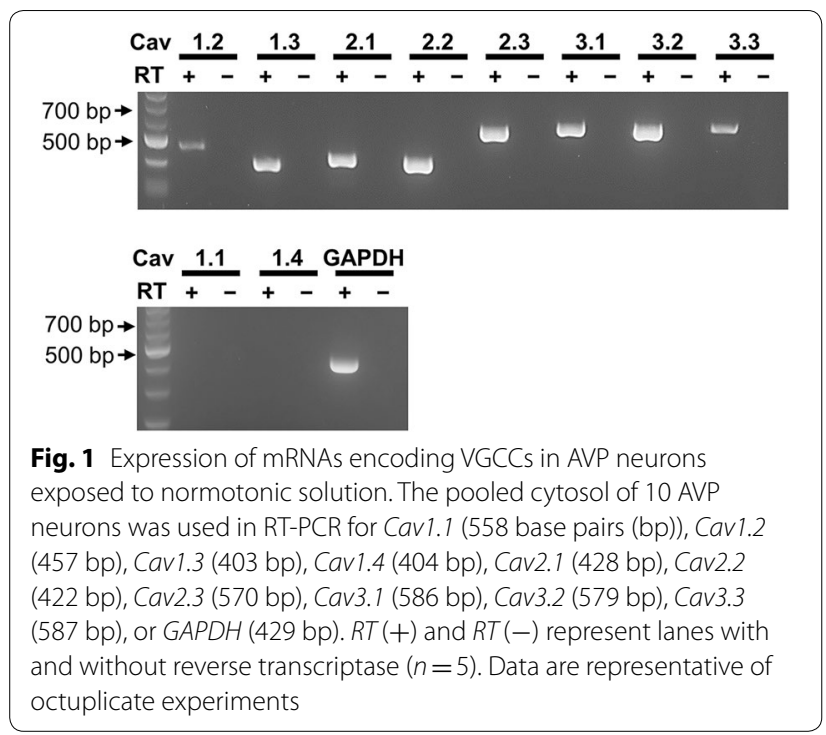

reactions. In contrast, PCR products for the skeletal muscle-type Cav1.1 and retinal-type Cav1.4 were not detected. The above eight Cav channel genes expressed in AVP neurons were completely matched by sequence analysis to the sequences corresponding to their respective rat Cav channels. These data indicate that unstimulated rat AVP neurons exhibit molecular expression of L-type Cav1.2 and Cav1.3, P/Q-type Cav2.1, N-type
Cav2.2, R-type Cav2.3, and T-type Cav3.1, Cav3.2 and Cav3.3 channels.

Next, we observed depolarization-induced $\mathrm{Ba}^{2+}$ currents to examine functional expression of VGCCs by whole-cell patch-clamp recordings in dissociated rat AVP neurons exposed to extracellular solution containing $\mathrm{Ba}^{2+}$ in place of $\mathrm{Ca}^{2+}$. As shown in Fig. 2, in the presence of $2 \mathrm{mM}$ and $50 \mathrm{mM} \mathrm{Ba}^{2+}$, voltagegated $\mathrm{Ba}^{2+}$ currents became activated at $>-60 \mathrm{mV}$ and $>-50 \mathrm{mV}$, and the peak currents were observed at around $-30 \mathrm{mV}$ and $-10 \mathrm{mV}$, respectively. Since the currents with $50 \mathrm{mM} \mathrm{Ba}^{2+}$ were much larger than those with $2 \mathrm{mM} \mathrm{Ba}^{2+}$, hereafter, whole-cell VGCC currents were observed in the presence of $50 \mathrm{mM}$ $\mathrm{Ba}^{2+}$. As shown in Fig. 3, VGCC currents were partially but significantly suppressed by either application of $\omega$-conotoxin GVIA $(\omega$-CgTx, $0.5 \mu \mathrm{M}$ : a, c), which is a specific blocker of $\mathrm{N}$-type $\mathrm{Ca}^{2+}$ channels [11-13], or that of $\mathrm{Ni}^{2+}$ ( $\left.3 \mathrm{mM}: \mathrm{b}, \mathrm{c}\right)$, which is known to exhibit an inhibitory effect on T-type $\mathrm{Ca}^{2+}$ channels [14, 15], and mostly suppressed by simultaneous applications of both $\omega-\mathrm{CgTx}$ and $\mathrm{Ni}^{2+}$ (c). As shown in Fig. 3c, it is noted that the peak VGCC currents were observed at $-10 \mathrm{mV}$ in the absence of any blockers (Control) and presence of $\omega-\operatorname{CgTx}(+\omega-C g T x)$, but those were shifted to $+10 \mathrm{mV}$ and $+20 \mathrm{mV}$ in the presence of $\mathrm{Ni}^{2+}$ and of $\mathrm{Ni}^{2+}$ plus $\omega-\mathrm{CgTx}\left(+\omega-C g T x+N i^{2+}\right)$, respectively. Also, the threshold voltage for VGCC activation

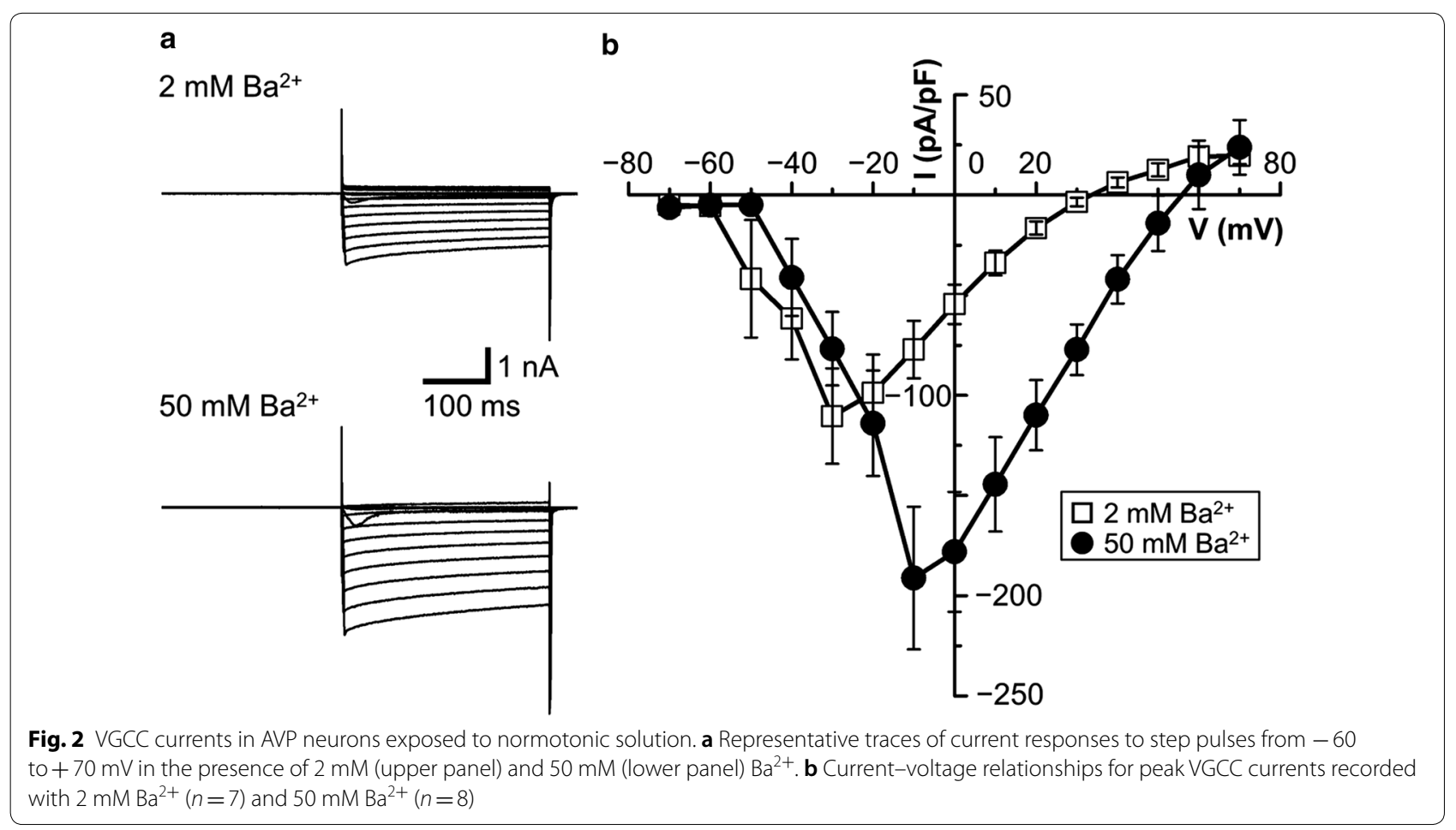




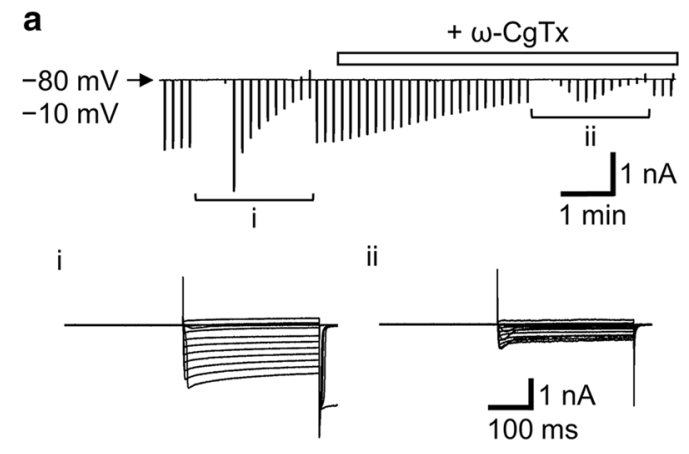

C

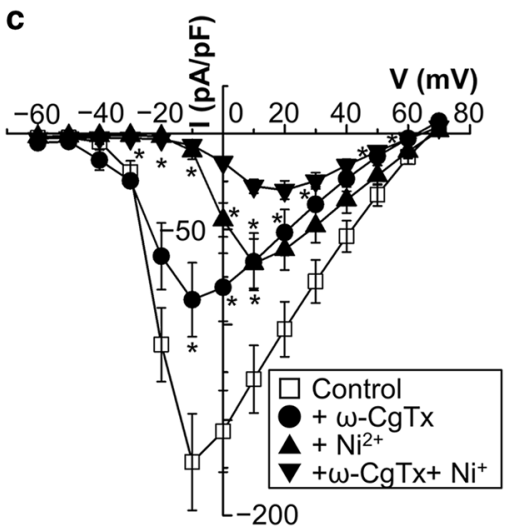

d

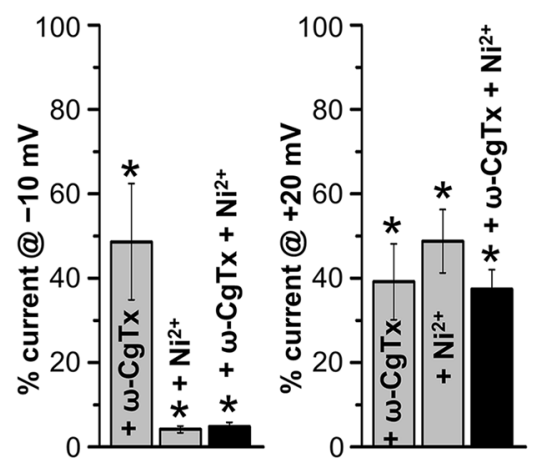

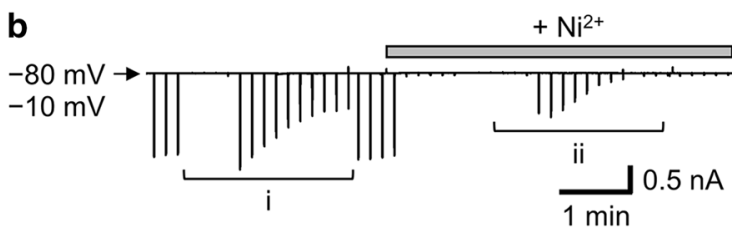

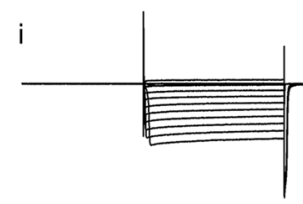

ii

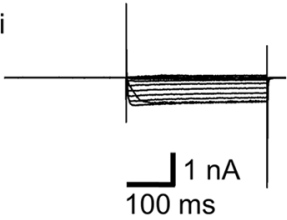

e

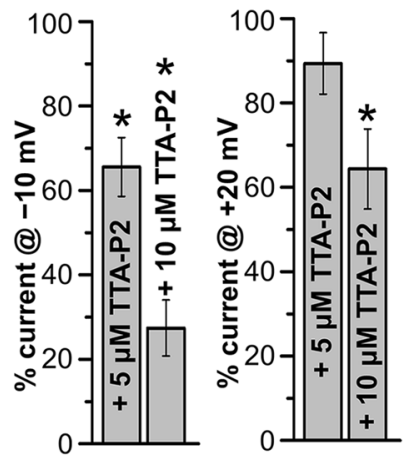

Fig. 3 Effects of $\omega$-CgTx, $\mathrm{Ni}^{2+}$ or $\omega$-CgTx plus $\mathrm{Ni}^{2+}$ on VGCC currents in unstimulated AVP neurons. $\mathbf{a}, \mathbf{b}$ Representative records of currents before and after application of $\mathrm{N}$-type $\mathrm{Ca}^{2+}$ channel blocker $\omega$-conotoxin GVIA ( $\omega$-CgTx $0.5 \mu \mathrm{M}$ : a) or T-type $\mathrm{Ca}^{2+}$ channel blocker $\mathrm{Ni}^{2+}(3 \mathrm{mM}$ : b) to AVP neurons exposed to normotonic solution containing $50 \mathrm{mM} \mathrm{Ba}^{2+}$. Inset panels given below the current traces in $\mathbf{a}$ and $\mathbf{b}$ represent expanded current responses to step pulses from -60 to $+70 \mathrm{mV}$ applied at $i$ and ii. c Current-voltage relationships for peak VGCC currents $(n=6-12)$. * $P<0.05$ vs. Control. d Percent currents at $-10 \mathrm{mV}$ (left panel) and $+20 \mathrm{mV}$ (right panel) in the presence of $\omega-\mathrm{CgTx}(n=6), \mathrm{Ni}^{2+}(n=8)$, and $\omega-\mathrm{CgTx}$ plus Ni ${ }^{2+}$ $(n=7)$ compared to the control currents (Control) in the absent of these blockers. ${ }^{*} P<0.05$ vs. Control. e Percent currents at $-10 \mathrm{mV}$ (left panel) and $+20 \mathrm{mV}$ (right panel) in the presence of 5 and $10 \mu \mathrm{MTTA}-\mathrm{P} 2(n=5)$ compared to the control currents (Control) in the absent of this blocker. * $P<0.05$ vs. Control

was -50 to $-40 \mathrm{mV}$ for Control and $+\omega-C g T x$, whereas that was positively shifted to -30 to $-20 \mathrm{mV}$ for $+\mathrm{Ni}^{2+}$ and $+\omega-\mathrm{CgTx}+\mathrm{Ni}^{2+}$. The inactivation time constant for $\omega$-CgTx-sensitive currents $(36.0 \pm 4.7 \mathrm{~ms}$, $n=7)$ was faster than that of $\mathrm{Ni}^{2+}$-sensitive currents $(70.0 \pm 10.4 \mathrm{~ms}, n=8)$. These results indicate that the VGCC currents are composed of $\mathrm{Ni}^{2+}$-sensitive lowvoltage-activated and $\omega$-CgTx-sensitive high-voltage-activated ones. Consistently, as summarized in Fig. 3d, the VGCC currents recorded at $-10 \mathrm{mV}$ were almost abolished by $\mathrm{Ni}^{2+}$ but only partially inhibited by $\omega-C g T x$, whereas those recorded at $+20 \mathrm{mV}$ were less effectively suppressed by $\mathrm{Ni}^{2+}$. As seen in Fig. 3 (c, d), there remains a minor part of high-voltage-activated VGCC currents resistant to $\mathrm{Ni}^{2+}$ and $\omega-\mathrm{CgTx}$, presumably L-, P/Q- and/or R-type ones. In addition, as summarized in Fig. 3e, application of $5 \mu \mathrm{M}$ 3,5-dichloro- $N$-[1-(2,2-dimethyl-tetrahydro-pyran- 4-ylmethyl)-4-fluoro-piperidin-4-ylmethyl]-benzamide (TTA-P2), which is known as a T-type-selective blocker [16], significantly, though partially, suppressed VGCC currents recorded at $-10 \mathrm{mV}$ (left panel) without significantly affecting the currents recorded at $+20 \mathrm{mV}$ (right panel). The VGCC currents recorded at $-10 \mathrm{mV}$ were markedly inhibited by $10 \mu \mathrm{M}$ TTA-P2 (Fig. 3e: left panel), but those recorded at $+20 \mathrm{mV}$ were also mildly suppressed (right panel). These results are consistent with the previous observations in dorsal root ganglion cells that TTA-P2 selectively inhibited T-type $\mathrm{Ca}^{2+}$ currents at $<10 \mu \mathrm{M}$, but TTA-P2 at $\geq 10 \mu \mathrm{M}$ inhibited, though less markedly, high-voltage-activated VGCC currents as well [17]. These pharmacological observations suggest that the VGCC currents are predominantly, though not all, composed of N-type (Cav2.2) and T-type $\mathrm{Ca}^{2+}$ channel activities in AVP neurons under normotonic conditions. 
a

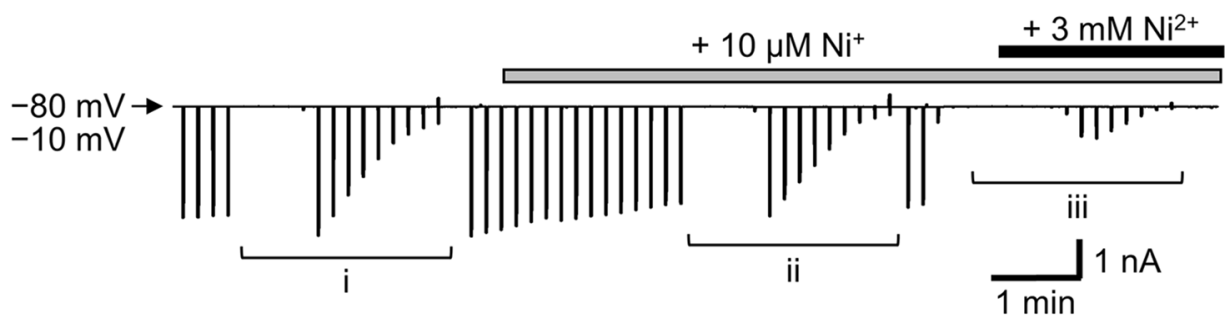

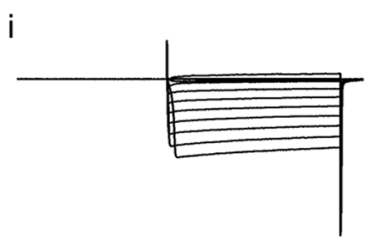

b

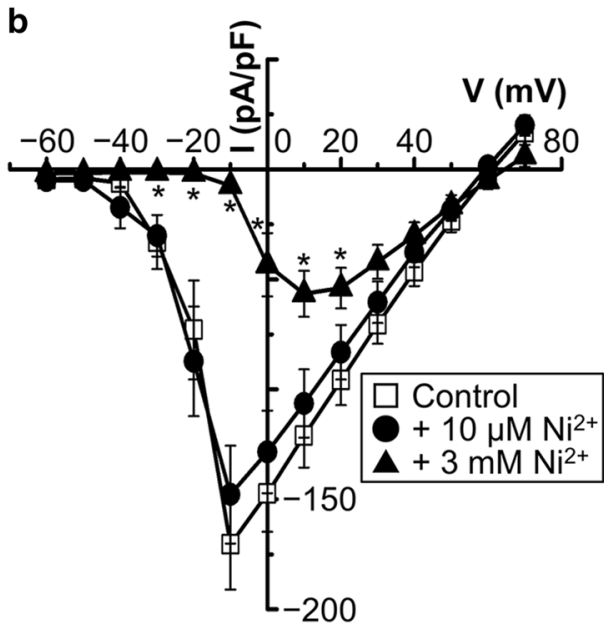

ii

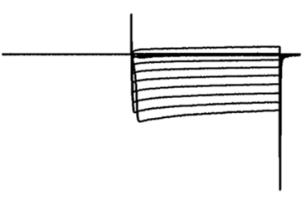

iii

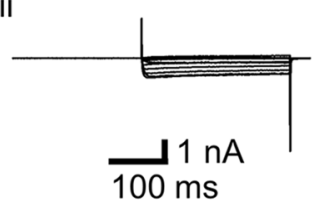

C

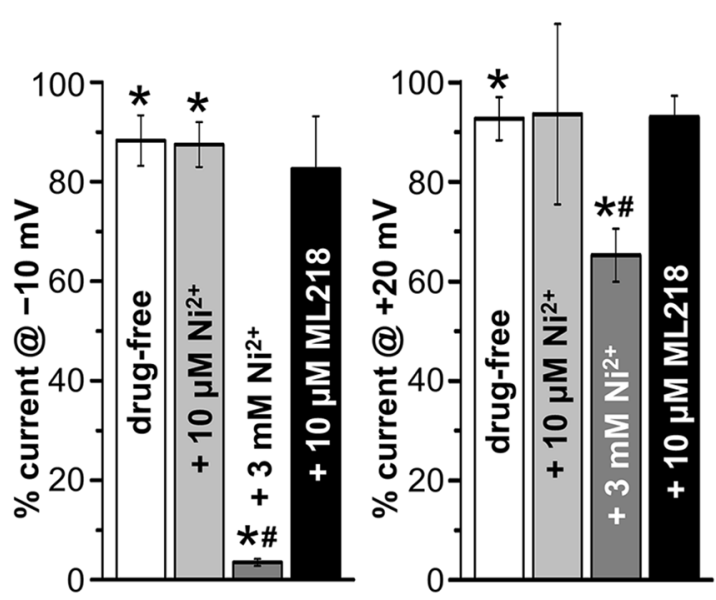

Fig. 4 Effects of $\mathrm{Ni}^{2+}$ and ML218 on VGCC currents in unstimulated AVP neurons. a Representative record of currents before and after application of a low concentration $(10 \mu \mathrm{M})$ or a high concentration $(3 \mathrm{mM})$ of $\mathrm{Ni}^{2+}$ to AVP neurons exposed to normotonic solution containing $50 \mathrm{mM} \mathrm{Ba}{ }^{2+}$. Inset panels given below the current trace represent expanded current responses to step pulses from -60 to $+70 \mathrm{mV}$ applied at $i$, ii and iii. b Currentvoltage relationships for peak VGCC currents $(n=8-12) . * 0<0.05$ vs. Control. c Percent currents at $-10 \mathrm{mV}$ (left panel) and $+20 \mathrm{mV}$ (right panel) after perfusion of control solutions $(n=8)$ containing no blockers (drug-free: $n=8), 10 \mu \mathrm{M} \mathrm{Ni}^{2+}(n=12), 3 \mathrm{mM} \mathrm{Ni}^{2+}(n=8)$, and $10 \mu \mathrm{M} \mathrm{ML218}(n=9)$ compared to the control currents (Control) recorded before perfusion. ${ }^{*} P<0.05$ vs. Control. ${ }^{\#} P<0.05$ vs. drug-free

Subsequently, we examined which of the T-type VGCCs of Cav3.1, Cav3.2 and Cav3.3 is functionally expressed in AVP neurons by observing the effects of $10 \mu \mathrm{M}$ and $3 \mathrm{mM} \mathrm{Ni}^{2+}$ (Fig. 4a,b). The VGCC currents showed a weak rundown by $11.8 \pm 5.1 \%$ at $-10 \mathrm{mV}$ and $7.32 \pm 4.3 \%$ at $+20 \mathrm{mV}$ (Fig. 4c: drug-free) after perfusion of bath solution over several minutes. Peak VGCC currents recorded at $-10 \mathrm{mV}$ were not significantly affected by the application of $10 \mu \mathrm{M} \mathrm{Ni}^{2+}$ (Fig. $4 \mathrm{a}-\mathrm{c}$ ), at which the Cav3.2 channel is known to be specifically blocked [14]. However, the currents recorded at $-10 \mathrm{mV}$ almost abolished and those recorded at $+20 \mathrm{mV}$ were less effectively but significantly suppressed by application of $3 \mathrm{mM} \mathrm{Ni}^{2+}$ (Fig. 4b,c), at which all Cav3.1, Cav3.2 and Cav3.3 channels are known to be inhibited $[14,15]$. Although $3 \mathrm{mM} \mathrm{Ni}^{2+}$ may not be precisely specific to T-type $\mathrm{Ca}^{2+}$ channels, $\mathrm{Ni}^{2+}$ almost completely suppressed the peak VGCC current observed at $-10 \mathrm{mV}$ at this concentration. Taken together with the TTA-P2 effects (Fig. 3e), it appears that the $\mathrm{Ni}^{2+}$-sensitive component observed at $-10 \mathrm{mV}$ represents mainly $\mathrm{T}$-type $\mathrm{Ca}^{2+}$ currents. In contrast to $\mathrm{Ni}^{2+}$ and TTA-P2, ML218 $(10 \mu \mathrm{M})$, which is a known blocker of both Cav3.2 and Cav3.3 channels [18], failed to significantly affect the depolarizationinduced $\mathrm{Ba}^{2+}$ currents (Fig. 4c), suggesting that only Cav3.1 is functioning as T-type $\mathrm{Ca}^{2+}$ channels in AVP neurons under normotonic conditions. 


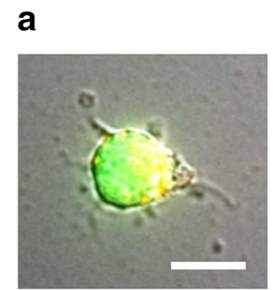

Control

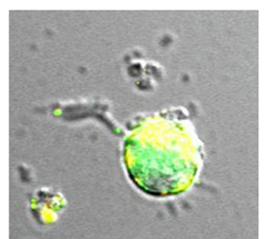

$\Delta$ Cav 2.2

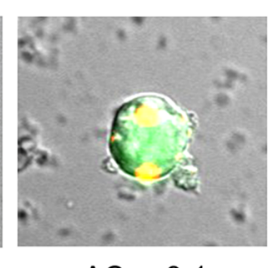

C

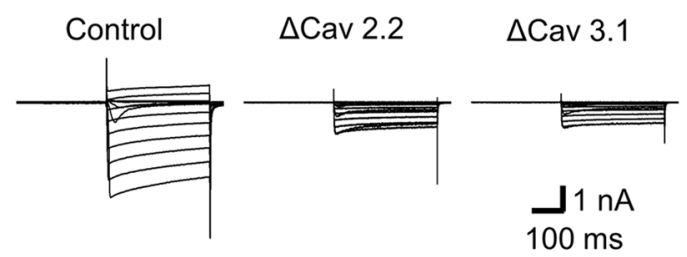

b
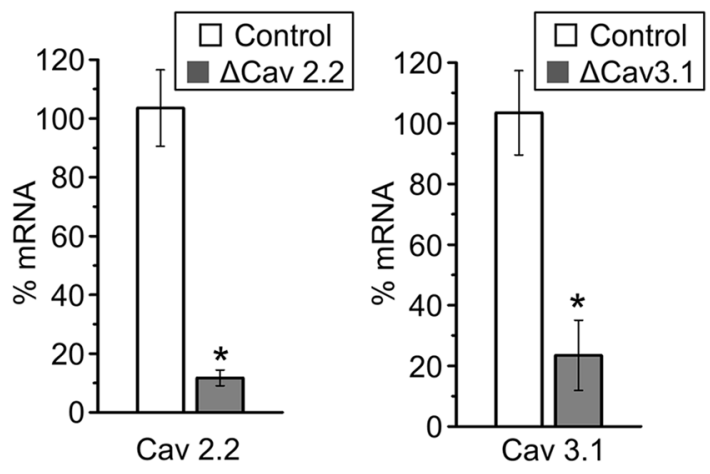

d

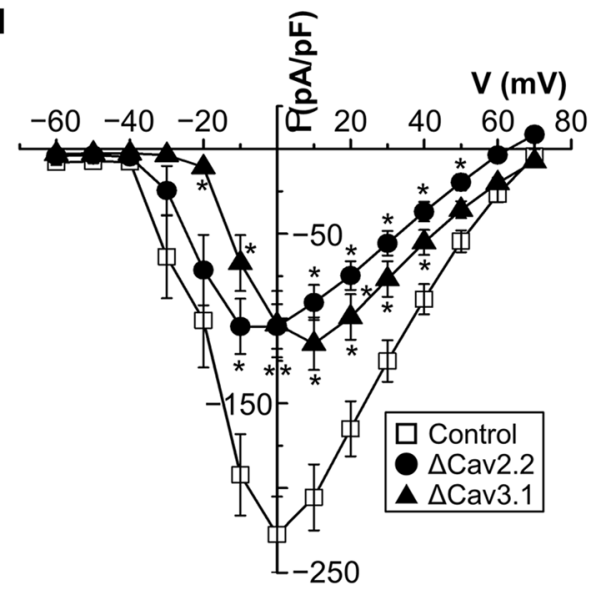

Fig. 5 Effects of siRNA-mediated knockdown of Cav2.2 or Cav3.1 on VGCC currents in unstimulated AVP neurons. a Representative fluorescence phase-contrast images among GFP-expressing AVP neurons transfected with DY547-labeled siRNAs for negative control (Control: left), Cav2.2 ( $\triangle$ Cav2.2: middle), and Cav3.1 ( $\triangle$ Cav3.1: right). We selected yellowish AVP neurons expressing GFP (green) and DY547 (red) together. Scale bar in the left panel indicates $10 \mu \mathrm{m}$. b Quantitative real-time PCR analysis of the expression of Cav2.2 and Cav3.1 in AVP neurons transfected with siRNAs specific to Cav2.2 ( $\triangle$ Cav2.2: left panel) and Cav3.1 ( $\triangle$ Cav3.1: right panel) as well as in negative control siRNA-transfected (Control) AVP neurons. Rat GAPDH mRNA was used as an internal control $(n=5-6)$. ${ }^{*} P<0.05$ vs. Control. c Representative traces of current responses to step pulses from -60 to $+70 \mathrm{mV}$ in AVP neurons transfected with siRNAs specific to Cav2.2 ( $\triangle$ Cav2.2: middle panel) and Cav3.1 ( $\triangle$ Cav3.1: right panel) as well as in negative control siRNA-transfected (Control: left panel) AVP neurons in normotonic solution containing $50 \mathrm{mM} \mathrm{Ba}^{2+}$. $\mathbf{d}$ Current-voltage relationships for peak

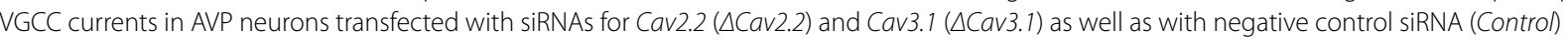
$(n=8-19) . *{ }^{*}<0.05$ vs. Control

We then examined the effects of siRNA-mediated single knockdown of Cav2.2 and Cav3.1 in AVP neurons. To do so, we selected yellowish neurons, as shown in Fig. 5a, expressing GFP-tagged AVP (in green) and DY547-tagged siRNAs (in red) for negative control (Control: left panel), Cav2.2 (middle panel), and Cav3.1 (right panel). Knockdown efficacy was confirmed by real-time PCR for Cav2.2 mRNAs (Fig. 5b, left panel) as well as for Cav3.1 mRNAs (Fig. 5b, right panel). As shown in Fig. 5 (c, d), VGCC currents were markedly suppressed by siRNA-mediated knockdown for Cav2.2 ( $\Delta$ Cav2.2) or Cav3.1 ( $\Delta$ Cav3.1). The peak currents for $\Delta$ Cav2.2 were observed at -10 to $0 \mathrm{mV}$, but those for $\Delta$ Cav3.1 were shifted to $+10 \mathrm{mV}$ (Fig. $5 \mathrm{~d}$ ). On balance, it is concluded that both high-voltage-activated N-type Cav2.2 and low-voltage-activated T-type Cav3.1 channels are not only molecularly, but also functionally expressed in rat AVP neurons under normotonic conditions.

\section{Both Cav2.2 and Cav3.1 channels are sensitive to FFA in rat AVP neurons}

We next examined effects of FFA, which was reported to inhibit not only a number of non-selective TRP cation channels in a variety of cell types [19-21], but also L-type $\mathrm{Ca}^{2+}$ channels in smooth muscle cells [22], on VGCC currents in rat supraoptic AVP neurons under conditions where extracellular and intracellular cations are replaced with TEA and NMDG, respectively, and thus non-selective cation channel currents were minimized. As shown in Fig. 6(a, d), to our surprise, FFA $(100 \mu \mathrm{M})$ partially but significantly suppressed VGCC currents in dissociated AVP neurons under normotonic conditions. The VGCC currents were also found to be significantly suppressed by $70 \mu \mathrm{M}$ FFA by $59.6 \pm 7.7 \%$ at $-10 \mathrm{mV}$ and $42.3 \pm 8.0 \%$ at $+20 \mathrm{mV}(n=5)$. At $100 \mu \mathrm{M}$, FFA markedly inhibited 


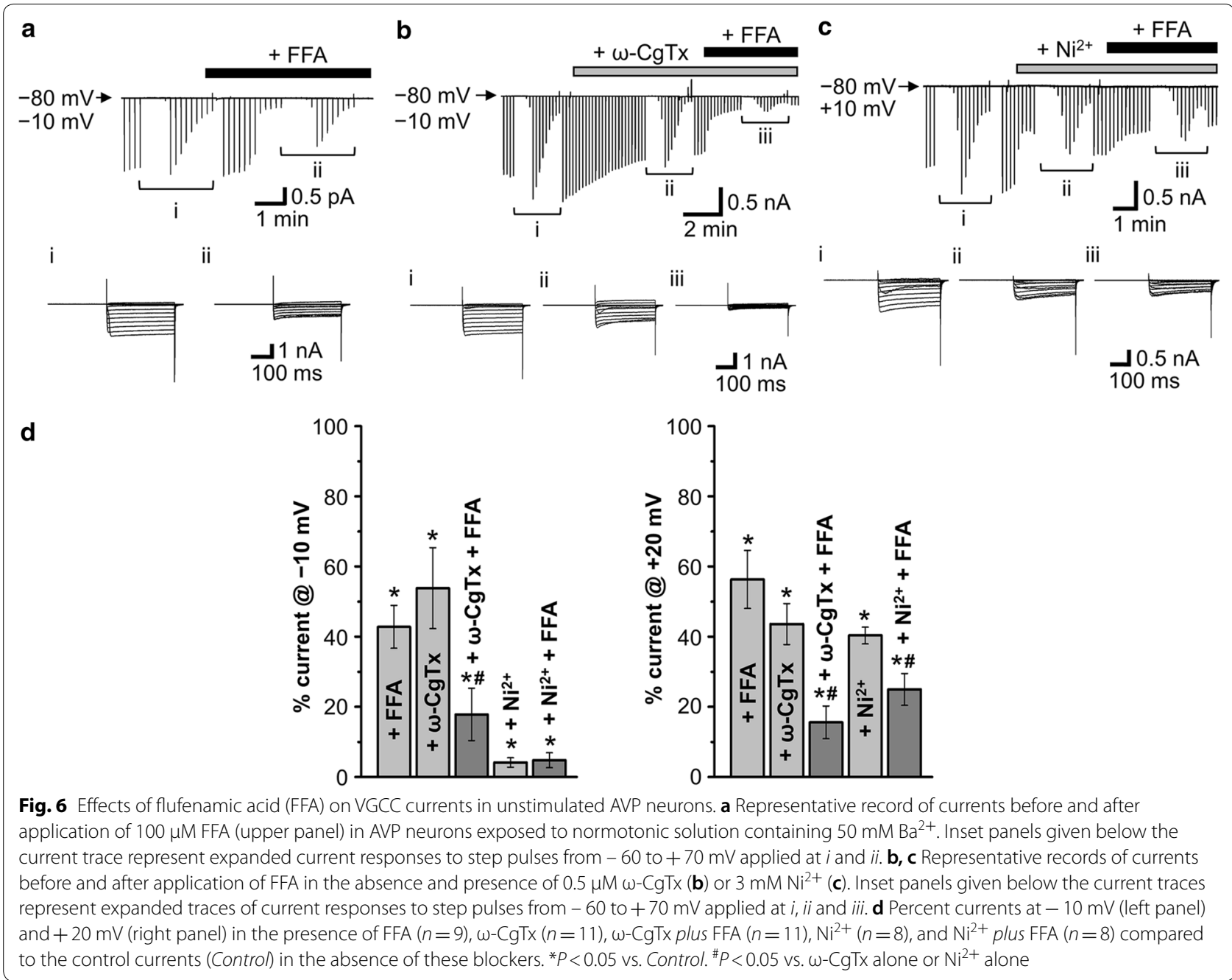

the $\omega$-CgTx-insensitive component of VGCC currents (Fig. 6b) but less markedly the $\mathrm{Ni}^{2+}$-insensitive component (Fig. 6c). As summarized in Fig. 6d, FFA significantly suppressed both the $\omega$-CgTx-insensitive components recorded at $+20 \mathrm{mV}$ and $-10 \mathrm{mV}$, whereas FFA inhibited the $\mathrm{Ni}^{2+}$-insensitive component recorded at $+20 \mathrm{mV}$ but not that recorded at $-10 \mathrm{mV}$. Taken together, it is clear that the FFA-sensitive component of currents are predominantly composed of T-type and N-type VGCC currents. These results show that both $\mathrm{N}$-type Cav2.2 and T-type Cav3.1 $\mathrm{Ca}^{2+}$ channels functionally expressed in the unstimulated rat AVP neurons are sensitive to FFA.

\section{FFA-sensitive T-type Cav3.1 channels are involved} in spontaneous firing activity in unstimulated AVP neurons To examine whether these FFA-sensitive VGCCs are essentially involved in the spontaneous action potential firing in unstimulated AVP neurons, we observed the effects of FFA on the spontaneous firing in dissociated rat AVP neurons by nystatin-perforated whole-cell current-clamp recordings under normotonic conditions. As shown in Fig. 7, the spontaneous firing was found to be very prominent under normotonic conditions. The spontaneous firing was clearly inhibited by a voltage-gated $\mathrm{Na}^{+}$channel blocker, tetrodotoxin (TTX, $0.5 \mu \mathrm{M})$. However, even in the presence of TTX, firing activity was maintained, though it became prominently less frequent. This TTX-insensitive firing activity was almost completely eliminated by additional application of FFA $(100 \mu \mathrm{M}$ : Fig. $7 \mathrm{a})$ or $\mathrm{Ni}^{2+}$ (3 mM: Fig. 7b), but not affected by $\omega$-CgTx $(0.5 \mu \mathrm{M}$ : Fig. 7c). As summarized in Fig. 7d, the firing frequency was significantly reduced by TTX and virtually nullified by FFA or $\mathrm{Ni}^{2+}$ added on top of TTX. These results indicate that not only TTX-sensitive $\mathrm{Na}^{+}$channels, but also FFAand $\mathrm{Ni}^{2+}$-sensitive Cav3.1 channels are involved in 


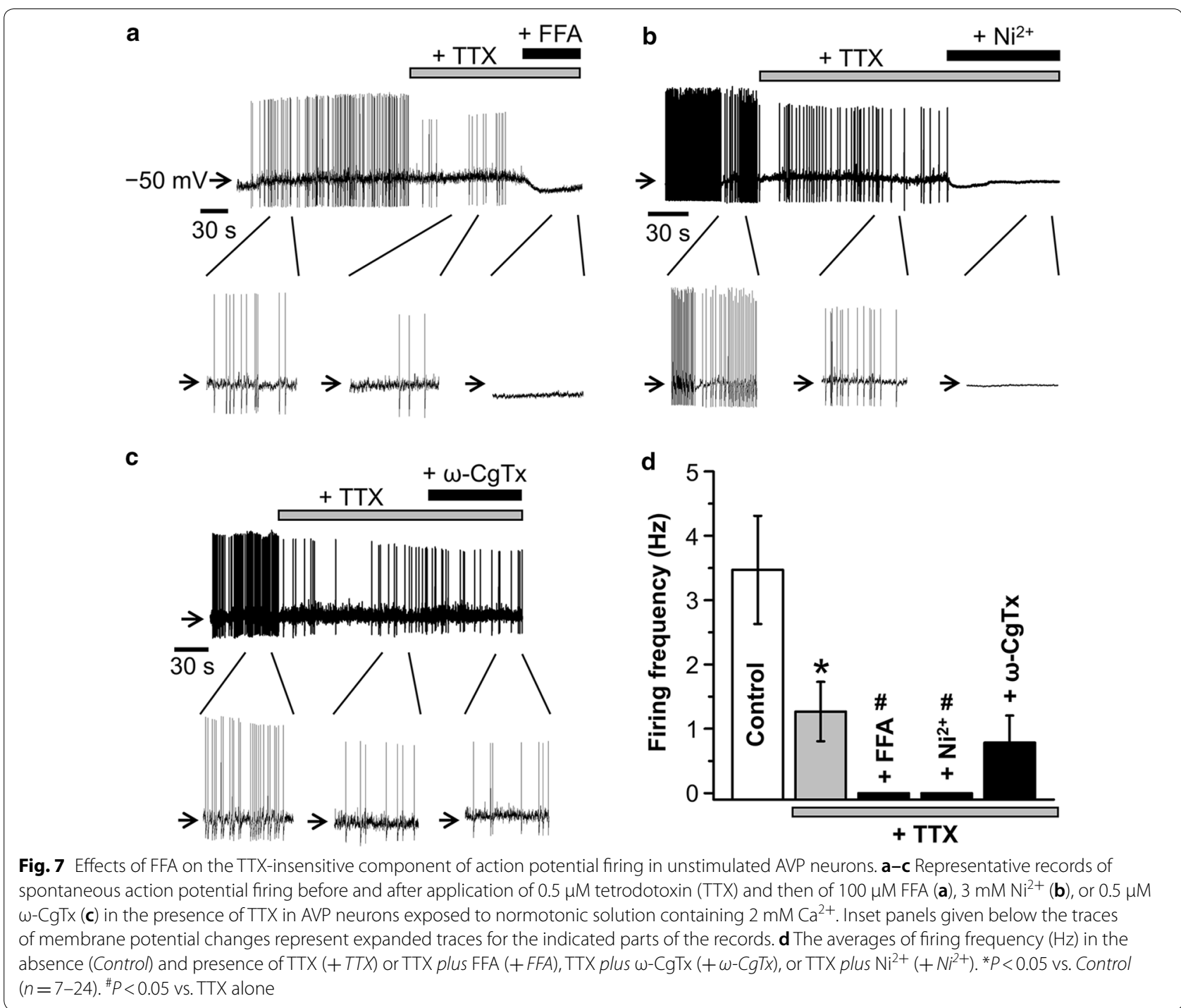

spontaneous firing activity in dissociated AVP neurons under unstimulated normotonic conditions.

\section{Discussion}

Release of AVP and oxytocin (OXT) from MNCs in the hypothalamus is evoked by $\mathrm{Ca}^{2+}$ influx through VGCCs $[5,23,24]$. Electrophysiological studies on VGCC currents showed that the soma of rat supraoptic MNCs functionally express T-, N-, L-, P/Q- and R-type $\mathrm{Ca}^{2+}$ channels [25-29]. However, increasing evidence has shown that there are some differences in important properties including ion channel activities and firing patterns between AVP and OXT neurons [30]. Thus, further studies have been warranted to be performed on VGCC activities in AVP neurons by distinguishing from those in OXT neurons, and vice versa. In both rat supraoptic AVP and OXT neurons, molecular expression of mRNAs for
non-T-type, high-voltage-activated $\mathrm{Ca}^{2+}$ channels were first reported by Glasgow et al. (1999) [31]. On the other hand, functional expression of T-type $\mathrm{Ca}^{2+}$ channels was observed in guinea pig supraoptic neurons, which likely represent AVP neurons displaying a depolarizing potential fired phasically [32]. Expression of T-, N- and L-type $\mathrm{Ca}^{2+}$ channels in rat supraoptic AVP neurons was indirectly suggested by observing sensitivity to VGCC blockers of the increases in the intracellular $\mathrm{Ca}^{2+}$ concentration $\left(\left[\mathrm{Ca}^{2+}\right]_{\mathrm{i}}\right)$ in response to AVP [6] and PACAP [7]. Direct electrophysiological studies showed functional expression of L-, $\mathrm{N}$ - and P/Q-type of $\mathrm{Ca}^{2+}$ channels in the neurohypophysial nerve terminals isolated from rats under unstimulated normotonic conditions [5]. However, these studies have not directly addressed the expression of VGCCs in AVP neurons largely devoid of their nerve 
terminals. In the present study, for the first time, expression of VGCCs was examined under unstimulated normotonic conditions in dissociated rat AVP neurons that were distinctly identified by transgenic eGFP expression. RT-PCR analysis showed that mRNAs for L-, P/Q-, N-, R- and T-type $\mathrm{Ca}^{2+}$ channels (Cav1.2 and Cav1.3, Cav2.1, Cav2.2, Cav2.3, and Cav3.1 to Cav3.3, respectively) were detected in the cytosol (Fig. 1). In dissociated rat AVP neurons, whole-cell VGCC currents were significantly inhibited, in an additive manner (Fig. 3), by $\omega$-CgTx, which is a known blocker specific for N-type Cav2.2 channels [11-13], and by a high concentration ( $3 \mathrm{mM})$ of $\mathrm{Ni}^{2+}$, which is known to predominantly block T-type Cav3.1, Cav3.2 and Cav3.3 channels [14, 15]. The VGCC currents sensitive to $\omega$-CgTx and to $\mathrm{Ni}^{2+}$ exhibited rapid and moderate inactivation rates (with $\tau$ of 36 and $70 \mathrm{~ms}$ ), which match the inactivation properties of T- and $\mathrm{N}$-type $\mathrm{Ca}^{2+}$ channels, respectively [33]. Expression of T-type $\mathrm{Ca}^{2+}$ channels in unstimulated rat AVP neurons is consistent with that of $\mathrm{Ni}^{2+}$-sensitive $\mathrm{Ca}^{2+}$ channels observed in unstimulated guinea pig AVP-like magnocellular neurons [32]. In contrast, $\mathrm{Ni}^{2+}$ failed to suppress the VGCC currents at $10 \mu \mathrm{M}$ (Fig. 4), the concentration of which was reported to block Cav3.2, but not Cav3.1 and Cav3.3, channels [14]. Also, the VGCC currents were insensitive to ML218 (Fig. 4c), which blocks Cav3.2 and Cav3.3 channels [18]. Taken together, it is concluded that Cav2.2 and Cav3.1 channels are predominantly functioning in the plasma membrane of unstimulated rat AVP neurons under normotonic conditions.

Low-voltage-activated or low-threshold T-type $\mathrm{Ca}^{2+}$ channels are activated at lower voltages than high-threshold L-, P/Q-, N- and R-type $\mathrm{Ca}^{2+}$ channels. Under physiological recording conditions, the apparent activation threshold for T-type $\mathrm{Ca}^{2+}$ channels is -50 to $-70 \mathrm{mV}$ (see Reviews [33, 34]). However, when the extracellular $\mathrm{Ba}^{2+}$ concentration was increased from 1 and $2 \mathrm{mM}$ to 10 and $40 \mathrm{mM}$, the threshold activation voltage for T-type $\mathrm{Ca}^{2+}$ channels was shown to be shifted by around 10 and $20 \mathrm{mV}$, respectively, to a positive direction, because of the effect of such high concentrations of $\mathrm{Ba}^{2+}$ on surface charge screening [35, 36]. In agreement with these facts, in the present study, the $\mathrm{Ba}^{2+}$ currents exhibited a threshold activation voltage of $>-60$ and $>-50 \mathrm{mV}$ in the presence of 2 and $50 \mathrm{mM} \mathrm{Ba}^{2+}$, respectively (Fig. 2). As a consequence, the voltage at which the peak currents were observed was also shifted from around $-30 \mathrm{mV}$ to $-10 \mathrm{mV}$, when extracellular $\mathrm{Ba}^{2+}$, was increased from 2 to $50 \mathrm{mM}$ (Fig. 2), suggesting that such a high concentration of $\mathrm{Ba}^{2+}$ caused formation of a positive surface potential, thereby shifted the voltage actually subjected to the $\mathrm{Ca}^{2+}$ channel protein toward a more negative one in the present study as well.
The present study also, for the first time, demonstrated that both N-type Cav2.2 and T-type Cav3.1 $\mathrm{Ca}^{2+}$ channels in AVP neurons are sensitive to FFA (Fig. 6). FFA has long been used therapeutically as one of the top prescribed non-steroidal anti-inflammatory drugs (NSAIDs) which exhibit anti-inflammatory, analgesic and antipyretic effects [37]. When $200 \mathrm{mg}$ FFA was orally administered to young healthy persons, the peak plasma concentration was reported to reach 6 to $20 \mu \mathrm{g} \mathrm{mL}{ }^{-1}$, or 21 to $71 \mu \mathrm{M}$, within $1.5 \mathrm{~h}$ [38]. Since FFA was shown to largely suppress both T- and N-type VGCC currents at 70 and $100 \mu \mathrm{M}$ in the present study in vitro, it is feasible that the endogenous VGCC activities, especially T-type one, in the axon terminal in situ are sometimes partially suppressed by the plasma FFA after oral administration, because the posterior pituitary region exists outside the blood-brain barrier [39].

Somatodendritic action potentials of rat supraoptic MCNs were previously shown to arise from co-activation of $\mathrm{Na}^{+}$and $\mathrm{Ca}^{2+}$ conductances [2]. However, it has not been known whether this is the case for AVP neurons distinguished from OXT neurons. In the present study, it was shown that the spontaneous firing in rat AVP neurons under unstimulated normotonic conditions is caused by the activities both of TTX-sensitive $\mathrm{Na}^{+}$channels and of FFA- and $\mathrm{Ni}^{2+}$-sensitive T-type Cav3.1 $\mathrm{Ca}^{2+}$ channels (Fig. 7). The time interval between spikes of around $490 \mathrm{~ms}$ may be sufficient to attain $\geq 90 \%$ recovery of T-type $\mathrm{Ca}^{2+}$ channel activity from inactivation, in light of previous data of around $90 \%$ recovery from short inactivation at $400 \mathrm{~ms}$ after firing of neuronal T-type $\mathrm{Ca}^{2+}$ channels [40]. When FFA was applied to AVP neurons in the presence of TTX, the membrane became hyperpolarized (Fig. 7a), whereas the resting potential was not much affected by $\mathrm{Ni}^{2+}$ and $\omega-\mathrm{CgTx}$ (Fig. 7b, c). Since FFA is known to suppress a number of the cation-permeable TRP channel family [19-21], it is suggested that FFAinduced hyperpolarization was caused by its inhibitory action to some of TRP cation channels in AVP neurons. Further studies are required to elucidate the contribution of each type of VGCC to the firing activity under hypertonic or prolonged dehydration/hydration conditions.

\section{Conclusions}

In dissociated rat AVP neurons under normotonic conditions, N-type Cav2.2 and T-type Cav3.1 VGCCs were found to be expressed and predominantly functioning, and be sensitive to FFA. Also, it is suggested that T-type Cav3.1 VGCC is primarily involved in their action potential generation in AVP neurons under normotonic conditions. 


\section{Abbreviations}

AVP: Arginine vasopressin; VGCC: Voltage-gated $\mathrm{Ca}^{2+}$ channel; FFA: Flufenamic acid; SON: Supraoptic nucleus; PVN: Paraventricular nucleus; MNCs: Magnocellular neurosecretory cells; OXT: Oxytocin; PACAP: Pituitary adenylate cyclaseactivating polypeptide; eGFP: Enhanced green fluorescent protein; GAPDH: Glyceraldehyde-3-phosphate-dehydrogenase; $\omega$-CgTx: $\omega$-Conotoxin GVIA; TTA-P2: 3,5-Dichloro-N-[1-(2,2-dimethyl-tetrahydro-pyran-4-ylmethyl)-4-fluoropiperidin-4-ylmethyl]-benzamide; TTX:Tetrodotoxin.

\section{Acknowledgements}

The authors thank N. Yasui for preparing chemicals and solutions employed for the experiments, looking after the animals, and helping establishment of the culture method of acute dissociated AVP neurons.

\section{Authors' contributions}

KSN conducted all experiments and analysis. TN and YU helped to design the work and commented on the draft. KSN and YO conceived and designed the work and wrote the manuscript. All authors read and approved the final manuscript.

\section{Funding}

This work was supported by Grants-in-Aid for Scientific Research (KAKENHI) from the Japan Society for the Promotion of Science (No. 18J40103).

\section{Availability of data and materials}

The data generated and/or analyzed during the current study are available from the corresponding author on reasonable request.

\section{Ethics approval and consent to participate}

All procedures performed in this study were in accordance with the regulations established at the Fukuoka University, with due consideration given to animal welfare and safety and health, and approved by the Ethics Committee of Animal Care and Experimentation, Fukuoka University, Japan (approval No.: 1906025).

\section{Consent for publication}

Consent for publication is not required for this article.

\section{Competing interests}

The authors declare that they have no competing interest

\begin{abstract}
Author details
1 Japan Society for the Promotion of Science, 5-3-1 Kojimachi, Chiyoda-ku, Tokyo 102-0083, Japan. ${ }^{2}$ Department of Physiology, School of Medicine, Fukuoka University, 7-45-1 Nanakuma, Jonan-ku, Fukuoka 814-0180, Japan. ${ }^{3}$ Department of Physiology, School of Medicine, University of Occupational and Environmental Health, 1-1, Iseigaoka, Yahatanishi-ku, Kitakyushu-shi, Fukuoka 807-8555, Japan. ${ }^{4}$ National Institute for Physiological Sciences, 5-1 Higashiyama, Myodaiji, Okazaki, Aichi 444-8787, Japan.
\end{abstract}

Received: 10 August 2020 Accepted: 28 September 2020 Published online: 15 October 2020

\section{References}

1. Bicknell RJ (1988) Optimizing release from peptide hormone secretory nerve terminals. J Exp Biol 139:51-65

2. Bourque CW, Renaud LP (1985) Calcium-dependent action potentials in rat supraoptic neurosecretory neurones recorded in vitro. J Physiol 363:419-428. https://doi.org/10.1113/jphysiol.1985.sp015719

3. Mason WT, Leng G (1984) Complex action potential waveform recorded from supraoptic and paraventricular neurones of the rat: evidence for sodium and calcium spike components at different membrane sites. Exp Brain Res 56:135-143. https://doi.org/10.1007/bf00237449

4. Poulain DA, Wakerley JB (1982) Electrophysiology of hypothalamic magnocellular neurones secreting oxytocin and vasopressin. Neuroscience 7:773-808. https://doi.org/10.1016/0306-4522(82)90044-6

5. Wang G, Dayanithi G, Kim S, Hom D, Nadasdi L, Kristipati R, Ramachandran J, Stuenkel EL, Nordmann JJ, Newcomb R, Lemos JR (1997) Role of Q-type $\mathrm{Ca}^{2+}$ channels in vasopressin secretion from neurohypophysial terminals of the rat. J Physiol 502(Pt 2):351-363. https://doi.org/10.1111/ j.1469-7793.1997.351bk.x

6. Sabatier N, Richard P, Dayanithi G (1997) L-, N- and T- but neither P- nor Q-type $\mathrm{Ca}^{2+}$ channels control vasopressin-induced $\mathrm{Ca}^{2+}$ influx in magnocellular vasopressin neurones isolated from the rat supraoptic nucleus. J Physiol 503(Pt 2):253-268. https://doi.org/10.1111/j.14697793.1997.253bh.x

7. Shibuya I, Kabashima N, Tanaka K, Setiadji VS, Noguchi J, Harayama N, Ueta Y, Yamashita H (1998) Patch-clamp analysis of the mechanism of PACAP-induced excitation in rat supraoptic neurones. J Neuroendocrinol 10:759-768. https://doi.org/10.1046/j.1365-2826.1998.00260.x

8. Zhang W, Star B, Rajapaksha WR, Fisher TE (2007) Dehydration increases L-type $\mathrm{Ca}^{2+}$ current in rat supraoptic neurons. J Physiol 580:181-193. https://doi.org/10.1113/jphysiol.2006.126680

9. Ueta Y, Fujihara H, Serino R, Dayanithi G, Ozawa H, Matsuda K, Kawata M, Yamada J, Ueno S, Fukuda A, Murphy D (2005) Transgenic expression of enhanced green fluorescent protein enables direct visualization for physiological studies of vasopressin neurons and isolated nerve terminals of the rat. Endocrinology 146:406-413. https://doi.org/10.1210/ en.2004-0830

10. Sato K, Numata T, Saito T, Ueta Y, Okada $Y(2011) V_{2}$ receptor-mediated autocrine role of somatodendritic release of AVP in rat vasopressin neurons under hypo-osmotic conditions. Sci Signal 4:5. https://doi. org/10.1126/scisignal.2001279

11. Kasai H, Aosaki T, Fukuda J (1987) Presynaptic Ca-antagonist omegaconotoxin irreversibly blocks $\mathrm{N}$-type Ca-channels in chick sensory neurons. Neurosci Res 4:228-235. https://doi.org/10.1016/01680102(87)90014-9

12. Plummer $M R$, Logothetis $D E$, Hess $P$ (1989) Elementary properties and pharmacological sensitivities of calcium channels in mammalian peripheral neurons. Neuron 2:1453-1463. https://doi.org/10.1016/08966273(89)90191-8

13. Williams ME, Brust PF, Feldman DH, Patthi S, Simerson S, Maroufi A, McCue AF, Veliçelebi G, Ellis SB, Harpold MM (1992) Structure and functional expression of an omega-conotoxin-sensitive human N-type calcium channel. Science 257:389-395. https://doi.org/10.1126/scien ce.1321501

14. Lee JH, Gomora JC, Cribbs LL, Perez-Reyes E (1999) Nickel block of three cloned T-type calcium channels: low concentrations selectively block alpha1H. Biophys J 77:3034-3042. https://doi.org/10.1016/s0006 -3495(99)77134-1

15. Rossier MF (2016) T-type calcium channel: a privileged gate for calcium entry and control of adrenal steroidogenesis. Front Endocrinol 7:43. https //doi.org/10.3389/fendo.2016.00043

16. Shipe WD, Barrow JC, Yang ZQ, Lindsley CW, Yang FV, Schlegel KA, Shu Y, Rittle KE, Bock MG, Hartman GD, Tang C, Ballard JE, Kuo Y, Adarayan ED, Prueksaritanont T, Zrada MM, Uebele VN, Nuss CE, Connolly TM, Doran SM, Fox SV, Kraus RL, Marino MJ, Graufelds VK, Vargas HM, Bunting PB, Hasbun-Manning M, Evans RM, Koblan KS, Renger JJ (2008) Design, synthesis, and evaluation of a novel 4-aminomethyl-4-fluoropiperidine as a T-type $\mathrm{Ca}^{2+}$ channel antagonist. J Med Chem 51:3692-3695. https://doi. org/10.1021/jm800419w

17. Choe W, Messinger RB, Leach E, Eckle VS, Obradovic A, Salajegheh R, Jevtovic-Todorovic V, Todorovic SM (2011) TTA-P2 is a potent and selective blocker of T-type calcium channels in rat sensory neurons and a novel antinociceptive agent. Mol Pharmacol 80:900-910. https://doi. org/10.1124/mol.111.073205

18. Xiang Z, Thompson AD, Brogan JT, Schulte ML, Melancon BJ, Mi D, Lewis LM, Zou B, Yang L, Morrison R, Santomango T, Byers F, Brewer K, Aldrich JS, Yu H, Dawson ES, Li M, McManus O, Jones CK, Daniels JS, Hopkins CR, Xie XS, Conn PJ, Weaver CD, Lindsley CW (2011) The discovery and characterization of ML218: A novel, centrally active T-type calcium channel inhibitor with robust effects in STN neurons and in a rodent model of parkinson's disease. ACS Chem Neurosci 2:730-742. https://doi.org/10.1021/cn200 090z

19. Lee YM, Kim BJ, Kim HJ, Yang DK, Zhu MH, Lee KP, So I, Kim KW (2003) TRPC 5 as a candidate for the nonselective cation channel activated by muscarinic stimulation in murine stomach. Am J Physiol Gastrointest Liver Physiol 284:G604-616. https://doi.org/10.1152/ajpgi.00069.2002 
20. Hill K, Benham CD, McNulty S, Randall AD (2004) Flufenamic acid is a $\mathrm{pH}$-dependent antagonist of TRPM2 channels. Neuropharmacology 47:450-460. https://doi.org/10.1016/j.neuropharm.2004.04.014

21. Albert AP, Pucovsky V, Prestwich SA, Large WA (2006) TRPC3 properties of a native constitutively active $\mathrm{Ca}^{2+}$-permeable cation channel in rabbit ear artery myocytes. J Physiol 571:361-369. https://doi.org/10.1113/jphys iol.2005.102780

22. Shimamura K, Zhou M, Ito Y, Kimura S, Zou LB, Sekiguchi F, Kitramura K, Sunano S (2002) Effects of flufenamic acid on smooth muscle of the carotid artery isolated from spontaneously hypertensive rats. J Smooth Muscle Res 38:39-50. https://doi.org/10.1540/jsmr.38.39

23. Tobin VA, Douglas AJ, Leng G, Ludwig M (2011) The involvement of voltage-operated calcium channels in somato-dendritic oxytocin release. PLoS ONE 6:e25366. https://doi.org/10.1371/journal.pone.0025366

24. Wang G, Dayanithi G, Newcomb R, Lemos JR (1999) An R-type Ca ${ }^{2+}$ current in neurohypophysial terminals preferentially regulates oxytocin secretion. J Neurosci 19:9235-9241. https://doi.org/10.1523/JNEUR OSCI.19-21-09235.1999

25. Fisher TE, Bourque CW (1995) Voltage-gated calcium currents in the magnocellular neurosecretory cells of the rat supraoptic nucleus. J Physiol 486:571-580. https://doi.org/10.1113/jphysiol.1995.sp020835

26. Fisher TE, Bourque CW (1995) Distinct omega-agatoxin-sensitive calcium currents in somata and axon terminals of rat supraoptic neurones. J Physiol 489(Pt 2):383-388. https://doi.org/10.1113/jphysiol.1995.sp021 059

27. Fisher TE, Bourque CW (1996) Calcium-channel subtypes in the somata and axon terminals of magnocellular neurosecretory cells. Trends Neurosci 19:440-444. https://doi.org/10.1016/0166-2236(96)10034-5

28. Foehring RC, Armstrong WE (1996) Pharmacological dissection of high-voltage-activated $\mathrm{Ca}^{2+}$ current types in acutely dissociated rat supraoptic magnocellular neurons. J Neurophysiol 76:977-983. https:// doi.org/10.1152/jn.1996.76.2.977

29. Joux N, Chevaleyre V, Alonso G, Boissin-Agasse L, Moos FC, Desarménien MG, Hussy N (2001) High voltage-activated $\mathrm{Ca}^{2+}$ currents in rat supraoptic neurones: biophysical properties and expression of the various channel alpha1 subunits. J Neuroendocrinol 13:638-649. https://doi.org/10.10 46/j.1365-2826.2001.00679.x

30. Armstrong WE, Foehring RC, Kirchner MK, Sladek CD (2019) Electrophysiological properties of identified oxytocin and vasopressin neurones. J Neuroendocrinol 31:e12666. https://doi.org/10.1111/jne.12666

31. Glasgow E, Kusano K, Chin H, Mezey E, Young WS 3rd, Gainer H (1999) Single cell reverse transcription-polymerase chain reaction analysis of rat supraoptic magnocellular neurons: neuropeptide phenotypes and high voltage-gated calcium channel subtypes. Endocrinology 140:5391-5401. https://doi.org/10.1210/endo.140.11.7136

32. Erickson KR, Ronnekleiv OK, Kelly MJ (1993) Role of a T-type calcium current in supporting a depolarizing potential, damped oscillations, and phasic firing in vasopressinergic guinea pig supraoptic neurons. Neuroendocrinology 57:789-800. https://doi.org/10.1159/000126438

33. Tsien RW, Lipscombe D, Madison DV, Bley KR, Fox AP (1988) Multiple types of neuronal calcium channels and their selective modulation. Trends Neurosci 11:431-438. https://doi.org/10.1016/01662236(88)90194-4

34. Huguenard JR (1996) Low-threshold calcium currents in central nervous system neurons. Annu Rev Physiol 58:329-348. https://doi.org/10.1146/ annurev.ph.58.030196.001553

35. Kaku T, Lee TS, Arita M, Hadama T, Ono K (2003) The gating and conductance properties of Cav3.2 low-voltage-activated T-type calcium channels. Jpn J Physiol 53:165-172. https://doi.org/10.2170/jjphysiol.53.165

36. Perez-Reyes E, Cribbs LL, Daud A, Lacerda AE, Barclay J, Williamson MP, Fox M, Rees M, Lee JH (1998) Molecular characterization of a neuronal low-voltage-activated T-type calcium channel. Nature 391:896-900. https ://doi.org/10.1038/36110

37. Mantas A, Mihranyan A (2020) Dissolution behavior of flufenamic acid in heated mixtures with nanocellulose. Molecules 25(6):1277. https://doi. org/10.3390/molecules25061277

38. Lentjes EG, van Ginneken CA (1987) Pharmacokinetics of flufenamic acid in man. Int J Clin Pharmacol Ther Toxicol 25:185-187

39. Landas S, Fischer J, Wilkin LD, Mitchell LD, Johnson AK, Turner JW, Theriac M, Moore KC (1985) Demonstration of regional blood-brain barrier permeability in human brain. Neurosci Lett 57:251-256. https://doi. org/10.1016/0304-3940(85)90500-2

40. Chemin J, Monteil A, Perez-Reyes E, Bourinet E, Nargeot J, Lory P (2002) Specific contribution of human T-type calcium channel isotypes (alpha(1G), alpha(1H) and alpha(1I)) to neuronal excitability. J Physiol 540:3-14. https://doi.org/10.1113/jphysiol.2001.013269

\section{Publisher's Note}

Springer Nature remains neutral with regard to jurisdictional claims in published maps and institutional affiliations.
Ready to submit your research? Choose BMC and benefit from:

- fast, convenient online submission

- thorough peer review by experienced researchers in your field

- rapid publication on acceptance

- support for research data, including large and complex data types

- gold Open Access which fosters wider collaboration and increased citations

- maximum visibility for your research: over 100M website views per year

At $\mathrm{BMC}$, research is always in progress.

Learn more biomedcentral.com/submissions 